\title{
FACTORS DETERMINING PARTICIPATION \\ OF THE ELDERLY IN SSI
}

Kathleen McGarry

Working Paper 5250

\author{
NATIONAL BUREAU OF ECONOMIC RESEARCH \\ 1050 Massachusetts Avenue \\ Cambridge, MA 02138 \\ September 1995
}

This paper is based on work originally presented in my doctoral dissertation at SUNY Stony Brook. I thank James N. Brown and Audrey Light for many helpful comments on earlier drafts, and Michael Hurd for valuable discussions on the current version of the paper. Financial support from NIA grant number T32-AG00186 to the NBER is gratefully acknowledged. Several suggestions from the editor resulted in substantial improvements to the paper. This paper is part of NBER's research program in Aging. Any opinions expressed are those of the author and not those of the National Bureau of Economic Research.

(C) 1995 by Kathleen McGarry. All rights reserved. Short sections of text, not to exceed two paragraphs, may be quoted without explicit permission provided that full credit, including $\odot$ notice, is given to the source. 


\title{
FACTORS DETERMINING PARTICIPATION \\ OF THE ELDERLY IN SSI
}

\begin{abstract}
The same low participation rates which plague many welfare programs have been observed among the elderly eligible for Supplemental Security Income (SSI). A number of hypotheses have been offered to explain the low enrollment, but none has attracted universal acceptance. In this paper I use the Survey of Income and Program Participation (SIPP) to examine the participation of the elderly in SSI. Because of the high quality of the data, I am able to determine eligibility more accurately than in most previous studies. In this sample, only 56 percent of those whom I determine to be eligible for SSI are presently receiving benefits. I model the decision to participate as a probit equation, but modify the likelihood function to account for measurement error in the expected benefit. The results indicate that participation is primarily determined by the financial situation of the eligible individuals. Although all those eligible for SSI are poor, those with little in the way of other resources are significantly more likely to participate. This finding differs from widespread beliefs that eligible individuals are discouraged by the difficulty of the application process, or that many are uninformed about the program.
\end{abstract}

\section{Kathleen McGarry}

Department of Economics

University of California, Los Angeles

405 Hilgard Avenue

Los Angeles, CA 90024

and NBER 


\section{Introduction}

If an individual is given an opportunity to increase his income with little or no effort, economic theory predicts that he will readily do so. Thus, an individual who is eligible for benefits from a public assistance program ought to enroll in the program, provided that the benefit he will receive is larger than the costs of participation. However, for many of the means tested government programs, the proportion of the eligible population which actually enrolls in the program is surprisingly low. Participation rates in the Aid to Families with Dependent Children program (AFDC) have been estimated at about 69 percent (Fraker and Moffitt, 1988) while those in the Food Stamp Program have been estimated to be around 40 percent (Fraker and Moffitt 1988, Coe 1977, and MacDonald 1977). For those elderly who are eligible for Supplemental Security Income (SSI), estimates of participation rates range between 45 percent and 60 percent (Sheilds et al. 1990, Coe 1985, and Menefee et al. 1981, Warlick 1982). The low rate apparent among the elderly is surprising because one would expect them to have few opportunities for improving their financial status. They should therefore be more dependent on this type of assistance than are the non-elderly. Assuming that these eligible nonparticipants behave as utility maximizing consumers, there must exist costs of participation which are not readily apparent. Such costs are often attributed to a welfare stigma (Moffitt 1983). However, it may also be the case that the costs of learning about the program or about one's eligibility, or the difficulty of actually applying are prohibitive. Without an understanding of the factors discouraging participation, it is difficult, if not impossible, to remedy the situation.

In this paper I focus solely on the participation decision of the elderly (65 and over). ${ }^{1}$ I propose a model of participation which allows non-monetary costs to enter into the participation decision. Because most hypothesized costs are unobserved, observable characteristics are used as proxies. While not providing a definitive explanation of nonparticipation, the use of these proxy variables permits a discussion of the relative importance of alternative explanations.

Previous studies which addressed the issue of non-participation in the AFDC, SSI, and Food Stamp Programs have been hampered by data limitations (Coe, 1977, 1985; Moffitt, 1983; and Warlick 1982 ). By using the Survey of Income and Program Participation (SIPP), I am able to

\footnotetext{
${ }^{1}$ With the available data it is not possible to determine accurately, eligibility based on disability or blindness.
} 
avoid most of the data problems evident in earlier work. SIPP contains comprehensive information on asset holdings and observations on monthly (rather than yearly) income. It also reports income from transfer programs relatively more completely than other surveys (Kalton, et al. 1986). Accurate information on measures of income and assets are necessary if eligibility is to be determined correctly.

Because eligibility rules and benefit guarantees vary widely across states, it is imperative that attention be paid to these differences in studies of participation. In calculating expected benefits, I treat observations from each state separately, using program characteristics specific to that state. Ignoring such state-to-state differences will cause substantial error in estimated benefits and eligibility.

In addition to providing better quality data than is available in other surveys, the time period covered by SIPP permits an interesting comparison. The data used in this study were collected during 1984,10 years after the SSI program began. The majority of previous research on participation in SSI, including the studies cited above, focused on participation during the initial years of the program's operations. Because it takes time to disseminate information about any new assistance program, participation rates in the early years may not be representative of current rates. By 1984 , any information lag responsible for depressing participation rates ought to be substantially eliminated.

This paper differs further from previous studies in that it controls for measurement error on an independent variable in a discrete choice model. As is typical in participation studies, an eligible unit's expected benefit is included as an explanatory variable. Because the benefit level is likely to include an error term (either from the assumptions required in the calculation procedure or from an error in reported information), a simple probit analysis, ignoring this error, will yield inconsistent estimates of the parameters. I focus solely on the error in this variable because the extensive computation involved in its construction makes it more subject to error than the other explanatory variables. To control for measurement error, I estimate the model using an instrumental variables technique.

The expected benefit is also used to determine who in the sample is eligible for SSI. Thus, measurement error will create an additional problem through the misclassification of eligible individuals. To control for misclassification I include observations which appear to be ineligible for 
SSI, as well as those determined to be entitled to a benefit. The likelihood function includes a term which controls for the probability with which the observation is in fact truly eligible. These results are compared with those obtained from the simple maximum likelihood estimation of the probit model which ignores the existence of measurement error.

As expected, I find that larger benefits significantly increase the probability that an individual will participate in the program. When observation error is controlled for, the magnitude of the coefficient of the expected benefit increases substantially. Estimates of the other parameters are, for the most part, unchanged. Without controlling for measurement error, a 25 percent increase in the benefit level increases the probability of participation by just 3.5 percentage points. However, when measurement error is accounted for, the same 25 percent increase in benefits induces a 6.1 percentage point increase in the probability of participating. I also examine the costs associated with enrolling in SSI and find evidence to discredit the role of a lack of information or the difficulty of the application procedure in deterring participation. I conclude that the decision to participate is based substantially on the level of need.

The next section briefly outlines the SSI program. Only those aspects of the program which are applicable to the elderly population are discussed. Because I use data from 1984, the laws pertaining to that year are explained. Section 3 presents the model of participation and examines the variables used in the model. Section 4 discusses the data and the measurement of the variables in the model while Section 5 discusses the estimation issues. The final two sections explore the implications of the model and summarize the results. It should be noted that the population examined in this study includes only those who are eligible for benefits as an aged person. The participation decision of blind and disabled individuals is ignored.

\section{Summary of the SSI program ${ }^{2}$}

Before the establishment of the Supplemental Security Income program, the elderly poor could apply for welfare from the state run programs of Old Age Assistance (OAA). These programs were administered by the individual states with some financing provided by the federal government. The generosity of the OAA programs and the eligibility requirements varied widely across states.

\footnotetext{
${ }^{2}$ The information about the federal SSI program in this section is taken from Social Security Administration (1988). The information pertaining to specific state programs is from Social Security Administration (1984).
} 
In 1972 Congress passed legislation which combined the state run assistance programs of OAA, Aid to the Blind (AB) and Aid to the Permanently and Totally Disabled (APTD), and created a federally funded and administered program called Supplemental Security Income (SSI). The SSI program became operational in January of 1974 under the management of the Social Security Administration. At the federal level, SSI provides a nationally uniform guaranteed income for the elderly (age 65 and over), the blind, and the disabled. The amount of the federal income guarantee differs only by marital status and living arrangements. Unlike other welfare programs, the federal SSI program makes no allowances for special needs. Rather, the amount of the benefit is well defined, calculated by subtracting an individual's or couple's monthly countable income from a guaranteed level. Countable income is obtained by subtracting a series of income disregards from total income. The basic disregards, determined on a monthly basis, include the first $\$ 20$ of unearned income, the first $\$ 65$ of earned income, and $1 / 2$ of any earned income in excess of $\$ 65 .^{3}$

In addition to the income requirements, applicants must also pass an asset test. Couples must have countable assets valued at less than $\$ 2250$ and singles must have less than $\$ 1500$ to be considered eligible. ${ }^{4}$ As is the case with income, several exclusions are made in the determination of asset holdings. The value of an owner occupied home, a car needed for medical treatment or for work, life insurance valued at less than $\$ 1500$, and personal property or household furnishings valued at less than $\$ 2000$ are all omitted.

In 1984 the monthly federal benefit for persons with no other income who lived in their own home was $\$ 314$. A married couple in the same circumstances received $\$ 472 .^{5}$ The income guarantee is reduced by $1 / 3$ if the filing unit (a single individual or married couple) lives in the household of another. The 1984 amounts for singles and couples in this category of recipiency were $\$ 209.34$ and \$314.67. These benefit levels are automatically adjusted each year to reflect changes in the CPI. The increase is calculated in a manner similar to that used to calculate increases in Social Security

\footnotetext{
${ }^{3}$ Also excluded from countable income are $\$ 20$ of unearned income and $\$ 10$ of earned income which are received irregularly or infrequently, home energy assistance payments, foster child care payments, some child support payments, grants to cover educational expenses, and death benefits which are used either to pay the medical expenses incurred during the deceased's last illness or to meet burial expenses.

${ }^{4}$ These levels were raised every year between 1985 and 1989 . The current values are $\$ 3000$ for a couple and $\$ 2000$ for a single individual.

${ }^{5}$ In order for a married couple to receive the couple's benefit, both spouses must be age 65 or over. If one spouse is less than age 65, the maximum benefit available is that of a single individual. To determine the amount of the transfer, a value is initially calculated as if both spouses were eligible. The actual benefit to which the eligible spouse is entitled is equal to the smaller of this calculated couple's benefit and the maximum available to a single individual.
} 
benefits. $^{6}$

When the federal government initially took control of the OAA programs, guarantees in some states were higher than the new guarantees offered by SSI. Rather than reduce the benefits for individuals in these states, the SSI legislation included a provision requiring states to supplement the payments of any individual whose total income under the new program would be less than that which they had previously received.

In addition to the federal program and these mandatory supplements, states have the option of voluntarily supplementing the federal grants for all or some recipients. This element of the SSI program introduces substantial variation in benefits between states. For example, in California the guarantee for a married couple living in their own home with no cooking facilities was $\$ 989$, an increase of $\$ 517$ over the federal level. In New Hampshire, however, the maximum benefit for a couple living in their own home was $\$ 473$, just $\$ 1$ over the federal value. ${ }^{7}$

If a state maintains the same basic eligibility guidelines as the federal program, the Social Security Administration will manage the supplemental program on behalf of the state, and absorb all administrative expenses. ${ }^{8}$ If a state is willing to incur the administrative expenses and run its own supplemental program, it may enact any eligibility criteria it wishes. In 1984, 43 states (including the District of Columbia) offered some type of voluntary supplement, compared to 34 states in the initial year of the program. Of the 43 states with optional supplemental programs, 26 administered their own programs and 17 were administered by the Social Security Administration. Regardless of the administrative agency, states may elect to impose liens on a recipient's property. These liens serve the purpose of repaying the state for its past contributions to the total SSI benefit and are enforced when the SSI recipient dies. ${ }^{9}$

In states which offer supplements, eligible individuals may elect not to apply for these additional benefits and collect SSI from the federal government only. ${ }^{10}$ Additionally, because of the alternative

\footnotetext{
${ }^{6}$ Although federal benefit level are indexed by the CPI, state supplemental benefits are not. Rather, increases are approved by the individual state legislatures.

${ }^{7}$ Unfortunately, this large variation across states cannot be used to explore differences in participation rates. The sample of eligible individuals in my sample is too small to support a disaggregated analysis.

${ }^{8}$ States are given some flexibility to modify the federal guidelines and still retain federal administration of the program. States may offer different maximum benefits for as many as 5 alternative living arrangements, and 2 geographic areas within the state. The varying levels by living arrangements are often used to provide additional payments to those requiring some amount of home care or medical attention. Payments based on geographic location are used to account for large differences in the cost of living within the state.

${ }^{9}$ In 1984 , only 6 states chose to impose such liens.

${ }^{10}$ The lien laws described above may provide motivation for this type of behavior.
} 
definitions of countable income it is possible for some of those who are eligible for a federal grant to be ineligible for the state supplement. The reverse situation may also occur. If an individual's countable income exceeds the federal guarantee, but is lower than the state grant, he may participate in the state program only. In $1984,500,919$ elderly people received both state and federal benefits, 215,353 received only state benefits, and 845,792 received SSI payments from just the federal government (Social Security Administration, 1985). Of those individuals with state benefits only, 31,777 received payments from state administered programs and 183,576 received payments from state supplemental programs which were administered by the Social Security Administration.

With the myriad of state supplemental program and participation rules, the SSI program has become more complex than a simple federal guaranteed income program. It does, however, provide a minimum level of income for all elderly persons. Unfortunately, because of the low participation rates, many of those who should benefit from the program are not receiving assistance. If the goal of the government is to insure a certain standard of living for all elderly persons, it is important to understand the causes of nonparticipation. The next section presents the model which I use to analyze the participation decision.

\section{Determination of Participation}

In 1984 the poverty line was $\$ 4979$ per year for a single elderly individual and $\$ 6275$ for an elderly couple (U.S. Bureau of the Census, 1986). In monthly terms these values are $\$ 415$ and $\$ 523$. The federal income guarantees from the SSI program are $\$ 314$ and $\$ 472$, which are well below the poverty line. Although most states supplement these levels, in 1984 only 4 states offered guarantees for both singles and couples which were above the poverty line. ${ }^{11}$ Surprisingly, despite the considerable poverty experienced by those eligible for SSI, it has been estimated that only about half of the eligible population is receiving benefits. If the paradigm of a utility maximizing consumer holds, it must be the case that for some individuals the utility obtained from participation and the associated increase in income is less than that derived from nonparticipation. ${ }^{12}$ In deriving the decision rule, I assume that an individual maximizes his utility subject to a budget constraint.

\footnotetext{
${ }^{11}$ SSI recipients are also categorically eligible for Medicaid in most states, and for food stamps in all states but California and Wisconsin. Thus, those availing themselves of SSI may be somewhat better off than these income amounts indicate.

${ }^{12}$ Throughout the discussion I assume that the decision to participate and actually receiving benefits are synonymous. I thus ignore the possibility that eligible individuals who chose to apply, may be unfairly denied benefits.
} 
Couples are treated as individuals in that they are assumed to maximize a single utility function and face a budget constraint based on their joint income.

The decision to participate is based on the incremental utility derived from participation. An individual chooses to enroll in SSI if the increase in utility, $P^{*}$, is positive. $P^{*}$ is equal to the total gain from participation, less any associated costs. The gain accruing from participation is a function of the expected monetary transfer, $B_{i}$ and other characteristics of the individual, $G_{i}$. The costs are represented by $C_{i}$ and also depend on individual differences. Thus,

$$
P_{i}^{*}=B_{i}+G_{i}-C_{i}
$$

$P_{i}^{*}$ is unobserved. Rather than $P_{i}^{*}$, one only observes the final decision, $P_{i}$, where

$$
P_{i}= \begin{cases}1 & \text { if } P_{i}^{*}>0 \\ 0 & \text { otherwise }\end{cases}
$$

The calculation of $B_{i}$ and the variables used to measure $G_{i}$ and $C_{i}$ are discussed in the following section.

Studies of participation in other programs (particularly AFDC) typically jointly model the decision to receive welfare and the number of hours worked because eligibility is endogenous to the labor supply decision. For the elderly population potentially eligible for SSI, the issue of labor force participation is relatively unimportant. In addition to income and asset restrictions, eligibility for the program as an aged (rather than blind or disabled) person requires that the individual be at least 65 years old. Thus, many of the participants have already retired. In the sample used in this paper, only 12 of the 554 eligible SSI units reported the receipt of labor earnings. ${ }^{13}$ One might wonder if many of those who are classified as ineligible would qualify for SSI were they to stop working. A careful examination of the data shows that this is not the case. Only 10 additional eligible units are obtained by excluding earnings from the calculation of countable income. Furthermore, these 10 units would likely receive Social Security to replace part of their lost earnings. An approximation of expected Social Security benefits shows that when earnings are omitted from countable income, but an estimated value of Social Security benefits is added, all of these individuals remain ineligible. ${ }^{14}$

\footnotetext{
${ }^{13} 27$ units, receive earnings at some time over the 1984 calendar year.

${ }^{14}$ I approximate Social Security benefits from data in Myers (1985). His estimates of OASDI benefits are calculated for earning levels in 1981 and based on retirement in 1982. Although the "calculation" I make is very rough, the results did not warrant a more careful examination.
} 
In principle, individuals could become eligible by disposing of assets. However, since 1980 the federal SSI regulations have prohibited the transfer of assets as a way of establishing eligibility. ${ }^{15}$ Any assets which are transferred for less than market value continue to be counted as part of the individual's asset holdings for two years and I ignore this possibility. This means that eligibility is pre-determined, and the participation decision is modeled as a single equation.

\section{Empirical Specification}

\subsection{The Data}

I estimate the model using data from the 1984 panel of the Survey of Income and Program Participation (SIPP). SIPP is a panel survey which interviews households in the non-institutional population every 4 months for approximately two and one-half years. Each four month period is referred to as a wave. In each wave respondents are asked to report information pertaining to each of the preceding 4 months. New panels are begun each year and follow the same format. Although more recent data is presently available, I use the 1984 panel because it is the largest. ${ }^{16}$

Because it reports both monthly income and total assets holdings, SIPP is well suited for this study. The benefit received from SSI is based on monthly income. Therefore, knowledge of monthly figures allows for a more accurate determination of eligibility than is possible from reports of yearly income given in most surveys. Furthermore, the fourth wave of SIPP contains a separate section which collects comprehensive information on asset holdings at that point in time. ${ }^{17}$ Although asset information is necessary if eligibility is to be determined correctly, the necessary information is not available in all data sets. Because of this limitation, many authors have been forced to ignore the asset test when determining eligibility (Moffitt 1983, Coe 1977). Others, including the Social Security Administration (in its studies using the CPS), impute the value of asset holdings by assuming that reported income from assets represents a 6 percent rate of return on total asset holdings.

From an initial sample of over 11,000 households, I select only those units (either single individuals or married couples) which I determine to be eligible to receive SSI benefits. Eligibility is defined as being age 65 or over and having income and asset levels below the maximum allowed by

\footnotetext{
${ }^{15}$ This restriction was loosened in 1987 and later tightened.

${ }^{16}$ Budget cut backs forced a reduction in sample size after wave 4 of the 1984 panel, and in subsequent panels.

${ }^{17}$ Wave 7 contains similar asset information but the sample is reduced somewhat prior to this interview.
} 
SSI regulations. ${ }^{18}$ To be included in the sample, I also require that the composition of the household in which the eligible unit resides remains constant between the fourth month of the sample period and the interview date. This restriction eliminates only 11 eligible units and is made for the following reason. Because the income data pertain to the month preceding the interview, and the asset information to interview date, this restriction helps to insure that the reported value of assets provides an accurate description of asset levels at the time for which the transfer is calculated. If the household composition changes between the fourth month and the interview date, the assets belonging to the household are also likely to have changed. Furthermore, because I use income from the previous wave as an instrumental variable (see section 5), I exclude those for whom no such information is available. An additional 6 units are eliminated by this restriction. The remaining sample consists of 554 units. $^{19}$

The sample of eligible individuals is composed predominately of widowed women. There are 408 single females, of whom 293 are widows, 68 single males, and 78 couples. In this sample of 554 units, 310 are receiving SSI benefits. This implies a participation rate of 56 percent. It is interesting to note how constant the participation rate has been over time. Using the 1973 and 1974 Survey of Low-Income Aged and Disabled Menefee et al. (1981) calculate a participation rate of 55 percent. $^{20}$

However, over the same time period, the number of poor elderly has declined considerably. Thus, although a similar fraction of those who are eligible, enroll in the program, a decrease in the size of the eligible population has resulted in a decline in the absolute number of elderly participants. In 1975, the number of persons over age 65 receiving SSI (either as disabled or aged persons) was just over 2.5 million. By 1984 this total had dropped to approximately 2.0 million (Zedlewski and Meyer, 1989).

Because the determination of a unit's eligibility hinges on a number of assumptions and relies

\footnotetext{
${ }^{18}$ If a married couple meets the income and asset qualifications but one spouse is younger than age 65 , eligibility is determined according to the federal regulations for this case (see footnote 5) and both spouses are included in the sample as part of an eligible unit.

${ }^{19}$ The descriptive work in this paper is based on this sample of households who appear to be entitled to SSI benefits. Later regressions augment this sample with households who would be eligible were their incomes lower, that is, those who are age 65 or over and who have countable assets below the SSI limits. These individuals are added because of a concern that measurement error in determining the eligible sample may bias the results. The total sample size for the final regression reported in the paper is therefore 1245.

${ }^{20}$ The Survey of Low-Income Aged and Disabled was conducted by the Social Security Administration specifically to evaluate the effectiveness of SSI. It therefore collected the information necessary to determine eligibility correctly. Thus their results ought to provide an accurate description of the eligible population.
} 
on the accuracy of reported income, the classification is subject to error. In this sample, 23 units which are classified as ineligible report that they are receiving SSI. It is possible that some of these units are truly ineligible, and are inappropriately receiving a benefit. The Social Security Administration estimates that 4 percent of those receiving benefits are ineligible (Social Security Administration, 1982). ${ }^{21}$ Additional explanations of this misclassification will become apparent in the following section.

The sample means of the variables used in this study are reported in Table 1. The values are reported for the entire sample of eligible individuals and separately for participants and nonparticipants. The amount of difference between the two populations is surprising given that they all have income and assets below the SSI limits and thus in this dimension are similar. The difference between the means is significant at the 1 percent level for all but 3 variables: age, whether the eligible unit lives with others, and whether SSI automatically entitles the unit to receive Medicaid. On average, participants have higher expected benefits, and thus lower pre-SSI incomes. The mean calculated benefit for participants is $\$ 176.89$ compared to $\$ 101.70$ for nonparticipants. The average monthly incomes, excluding SSI, for the two groups are $\$ 208.90$ and $\$ 320.89$. Participants also have somewhat less schooling, are less likely to own a home or other assets, and are less likely to receive earnings or Social Security benefits.

Although SIPP is a panel data set, little information is gained by exploiting this aspect of the survey. Only 13 of the units who report receiving SSI at some time during the four month period have any change in their reported benefit. These changes are typically minor, and likely to be due to reporting or coding errors. Five of these units appear to begin collecting benefits, while none apparently leaves the SSI rolls. Somewhat more movement is observed by following individuals across the first four interview periods, though for the most part, the changes seem minor. ${ }^{22}$

\subsection{Benefit Calculation}

Benefit levels are only observed for those in the sample who actually receive SSI, and as mentioned previously, this figure may not reflect benefits received from state administered programs. I therefore calculate expected payments for each eligible unit using state specific regulations as described

\footnotetext{
${ }^{21}$ Sheilds et al. find that 10 percent of those reporting the receipt of Social Security benefits were determined to be ineligible by their simulation model.

${ }^{22}$ The small number of changes is in part a result of seam bias in SIPP.
} 
in U.S. Department of Health and Human Services (1984). When estimating the model, I use the calculated value of benefits for both program participants and nonparticipants. The details of the procedure for calculating benefits are discussed in the appendix.

The use of state--specific guarantees and income exclusions is crucial if expected benefits are to be determined accurately. Because the program regulations vary widely between states, using only the size of the federal benefit will likely seriously bias the results. As discussed earlier, approximately 14 percent of the participating population receives state benefits only. Furthermore, the units who receive benefits only from the federal program are not a random sample of the eligible population. Rather, they would be expected to have higher incomes, and thus, lower benefits. Because the probability of participation is typically found to be positively correlated with the size of the benefit, the exclusion of this group of eligibles is likely to result in an overestimate of the participation rate. For the sample used in this paper, the participation rate changes from 56 percent to 60 percent when only federal eligibility is considered. Additionally, those who are eligible at the federal level may receive substantially higher benefits when the state supplements are taken into account. Thus the importance of the size of the benefit in determining participation may be obscured if state benefits are not taken into account. ${ }^{23}$

The mean calculated benefit is $\$ 177$ for participants and $\$ 102$ for nonparticipants. ${ }^{24}$ This difference is consistent with the hypothesis that those with higher benefits are more likely to participate than those with lower expected benefits. The median benefit amounts for participants and non-participants are $\$ 149$ and $\$ 76$. However there are many among the non-participants who forgo sizable assistance. Fourteen percent of non-participants have estimated benefits above $\$ 200$ a month, 22 percent above $\$ 150$.

The calculated amounts agree well with the reported payment levels. For the 310 eligible units in the sample who are presently receiving SSI, the correlation between the calculated benefit and the reported value is 0.84 , and the calculated value is within $\$ 1$ of the reported amount for 121 cases. Thus, it appears that the calculated benefit is a good approximation of the actual amount to which a particular filing unit is entitled.

\footnotetext{
${ }^{23}$ Warlick (1982) uses only the federal guidelines to determine eligibility. As she discusses, her results should be interpreted with caution.

${ }^{24}$ Scaling the benefits by separate price indices for each of the four Census regions (Northeast, North Central, South and West) resulted in no change in the estimates. The majority of variation in the price level is between rural and urban areas rather than between regions of the country. A urban/rural dummy is included in the model.
} 


\subsection{Differences in the Marginal Value of the Benefit}

While all those who are eligible for SSI are without question poor, there is also substantial disparity in their economic situation. For example, some individuals may own a home, a car, or be able to obtain some type of job should additional income be needed, whereas others have no resources to provide even a small amount of financial security. The utility derived from a given amount of the SSI benefit, may thus differ widely across individuals. To account for the difference in the empirical estimation, I use a series of variables which are indicative of financial status. I include dummy variables indicating ownership of a home, a car, or non-zero holdings of countable assets, and a variable equal to the ratio of the unit's pre-SSI income to the poverty line. Similarly, some individuals may face temporary spells of poverty or, in this case, eligibility. If they expect to become ineligible in the near future, the marginal value of the benefit would be less than if these benefits were expected to continue indefinitely. ${ }^{25}$ To proxy the relative permanence of the current eligibility status I use the variance of monthly income over the calendar year. Marital status, to some extent, may also proxy the permanence of the present economic situation. As shown in Hurd and Wise (1989), couples who are initially observed in poverty are less likely to be permanently poor than are single individuals. A dummy variable which equals one if the eligible unit is a married couple is also included in the model. All of these factors are expected to be negatively correlated with the probability of participation.

In 1984 SSI recipients in 32 states were categorically eligible for Medicaid. Although Medicare benefits are available to those over 65 who are receiving Social Security, Medicare does not meet all medical expenses. Individuals in poor health, and those with low incomes may need additional assistance to pay for any uncovered costs. Furthermore, those without Medicare, or private health insurance would be expected to need some form of medical insurance. Many states have Medically Needy programs which offer Medicaid to the needy poor without requiring enrollment in SSI, but as discussed in Blank (1989), this type of program involves much additional paper work to document medical expenses and may therefore be more "costly" than applying for SSI itself. The joint benefit

\footnotetext{
${ }^{25}$ In theory, one would like to include the expected value of the entire stream of benefits from SSI. Such a variable ought to be calculated from the point in time at which the unit first becomes eligible. However, with the given length of the panel, it is not possible to observe the initial period of eligibility for most in the sample. The interaction of age with the expected benefit was tried as a proxy for the expected stream of benefits. This term was not significantly different from zero.
} 
received from participation in SSI and automatic Medicaid eligibility may be significantly larger than the benefit from SSI alone. To test this hypothesis, I use a dummy variable indicating poor health, another which equals 1 if the state automatically entitles SSI recipients to Medicaid, and the interaction of these two variables. ${ }^{26}$

\subsection{Measurement of Costs of Participation}

In addition to receiving monetary benefits, an individual who enrolls in SSI may incur a number of fixed costs. Ideally one would like to have a direct measure of these costs. However, the explanations of nonparticipation which have been put forth in the literature, such as information barriers, the difficulty of the application procedure, and the stigma associated with participation in a welfare program, are all unobserved. These are therefore proxied by observable characteristics. The following discussion provides a rationale for using each proxy variable to represent costs of participation. It uses many of the same theories of nonparticipation that have been proposed elsewhere. Warlick (1979) contains a comprehensive summary of the various theories, each of which will be mentioned only briefly here.

The availability of a car, living in a MSA, living with others, and poor health, can all be theorized to proxy the ease of getting to the Social Security office. Those who live in a household in which someone owns a car, or who live with relatives or friends, ought to have less difficulty in arranging transportation to the local office. Similarly, residence in a metropolitan area ought to be positively correlated with the availability of public transportation, and thus with the easy of traveling to a Social Security office.

If individuals do not participate because the application process itself is too difficult, then those with more years of schooling ought to be more likely to participate holding everything else constant. Also, those who are receiving Social Security have applied for these benefits and may be better acquainted with the type of bureaucratic procedures involved, and more likely to enroll.

\footnotetext{
${ }^{26}$ I require information on an individual's state of residence in order to determine Medicaid eligibility. There are several states which for confidentiality reasons not individually identified. Observations from four Western states (Idaho, New Mexico, South Dakota, and Wyoming) are grouped together as are observations from two Southern states (Mississippi and West Virginia). The procedure used in these cases to determination Medicaid eligibility is the same as that used in the calculation of benefits and which is described in the Appendix. Briefly, I select the least. generous of program within the each group and assume that this particular regulation holds across the region. For example, SSI recipients are not automatically eligible for Medicaid assistance in Idaho, thus no one in this group of four western states is assumed to be automatically eligible. As in the case of benefit determination, no difficultly results from the aggregation of observations from Mississippi and West Virginia. SSI recipients are categorically eligible for Medicaid in both states.
} 
Eligible individuals may fail to participate because they are unaware of the program's existence. If this were the case, then those who reached age 65 when the program was already in operation ought to be more likely to participate than older people. It is also possible that older individuals may have initially applied for benefits from the original state run OAA program, and were found to be ineligible. This original denial may lead them to believe that they will not presently qualify for benefits. Thus, a dummy variable which equals one if the individual reached age 65 after the program began (1974 or later), and zero otherwise is included in the model. If this hypothesis of a cohort effect is correct, then this variable should have a positive coefficient, indicating that younger individuals are more likely to participate. ${ }^{27}$

In addition, because SSI is administered by the Social Security Administration, primary methods of informing potential beneficiaries of the program's existence include notifying new applicants for Social Security and mailing information about the program along with Social Security checks making it more likely that Social Security recipients are aware of the program. Thus, those receiving Social Security benefits ought to be better aware of the program's existence than those without such benefits, and therefore more likely to take advantage of SSI. Individuals with more schooling would likewise be expected to be more well informed. Under the same premise, those living in an MSA or with others may interact more with individuals in similar circumstances and be more likely to hear about SSI.

It is also widely believed that individuals may feel stigmatized by accepting welfare. To proxy this stigma effect, I use residence in a southern state, residence in an MSA, the receipt of other welfare, age and race. It has been theorized that those in the South attach less of a stigma to the receipt of welfare than individuals in other regions of the country (Baldus, 1973), as do those living in urban areas (Osgood, 1977). If this hypothesis is true then, ceteris paribus, those who live in southern states or in urban areas would be more likely to participate in SSI than residents of other regions. Because older individuals are assumed to be more reluctant to accept assistance, age should also be negatively related to participation. It has also been argued that non-whites are less affected by any stigma associated with participation in a welfare program (Strauss 1977). Race is therefore included to capture any such difference. Finally, if one receives welfare from more than

\footnotetext{
${ }^{27}$ Using actual age rather than this dummy variable, or the difference between the year in which the individual turned 65 and the first year of the SSI program led to identical results.
} 
one program, the stigma associated with participation in each individual program ought to be of less concern. If the stigma results from accepting assistance rather than the amount of the transfer, then for those enrolled in multiple programs the amount of "stigma per program" ought to be less, and they should more readily enroll in SSI. ${ }^{28}$

\section{Estimation}

In the reduced form of model, the terms $G_{i}$ and $C_{i}$ are expressed as a linear function of a vector of the observable variables $\mathbf{X}_{\mathbf{i}}$. That is,

$$
G_{i}-C_{i}=\mathbf{X}_{\mathbf{i}} \alpha+e_{i}, e \sim N\left(0, \sigma_{e}^{2}\right)
$$

where $\alpha$ is a vector of coefficients to be estimated and $e_{i}$ is a normally distributed error term with zero mean and variance $\sigma_{e}^{2}$. The model is therefore

$$
P_{i}^{*}=\delta B_{i}+\mathbf{X}_{\mathbf{j}} \alpha+e_{i}
$$

where

$$
P_{i}= \begin{cases}1 & \text { if } P_{i}^{*}>0 \\ 0 & \text { otherwise }\end{cases}
$$

The variables included in the vectors $\mathbf{X}_{\mathbf{i}}$ are listed in Table $2 .{ }^{29}$ As it is currently written, the model is a simple probit equation and can be estimated straightforwardly by maximum likelihood techniques. However, if consistent estimates are to be obtained, one must recognize the existence of measurement error and respond accordingly. The procedure used to calculate a filing unit's benefit involves several assumptions which may or may not be valid. Additionally, the accuracy of the calculated benefit depends directly on the correctness or availability of other information. As a result, the calculated benefit is likely to contain a non-trivial amount of error.

For the other explanatory variables in the model, the effect of measurement error is less likely to be an issue. With the exception of the level of schooling, the variation in income, and the ratio of income to the poverty line, the variables are all dummy variables. Observation error will affect the results only to the extent that it is large enough to change the category in which the

\footnotetext{
${ }^{28}$ Moffitt (1983) models stigma as being comprised of both a fixed component, dependent only on whether or not an individual receives assistance, and a variable effect which depends on the size of the benefit. He does not find a significant variable component.

${ }^{29}$ Interactions between the expected benefit and various independent variables and between the variance of income and other terms were insignificant.
} 
individual is observed. Furthermore, the accuracy of many of these variables can be confirmed by comparing data from different interviews. Such a comparison shows little inconsistency. For the variables constructed from observed income, measurement error is more likely to be a problem. However, given the data requirements and the assumptions necessary to calculate the expected benefit, it appears reasonable to assume that the errors associated with income are small relative to the combination of errors which may affect the measure of the SSI transfer. I therefore ignore the possibility of measurement error on all terms except the calculated benefit.

Measurement error in the calculated benefit affects the estimation in two ways. First, in the probit equation, it creates an errors-in-variables problem with the added twist of a non-linear specification. Secondly, because I classify individuals as eligible or ineligible based on the calculated benefit, this classification is subject to error. Below I discuss the solution to these potential problems in turn.

If $B_{i}^{*}$ denotes the true payment to which the unit is entitled and $u_{i}$ denotes the difference between this value and the calculated amount,

$$
\begin{aligned}
P_{i}^{*} & =\delta B_{i}^{*}+\mathbf{X}_{\mathbf{i}} \alpha+e_{i} \\
\text { and } B_{i} & =B_{i}^{*}+u_{i}, u \sim N\left(0, \sigma_{u}^{2}\right) . \\
\text { Thus } P_{i}^{*} & =\delta\left(B_{i}-u_{i}\right)+\mathbf{X}_{\mathbf{i}} \alpha+e_{i} \\
& =\delta B_{i}+\mathbf{X}_{\mathbf{i}} \alpha-\delta u_{i}+e_{i}
\end{aligned}
$$

and again,

$$
P_{i}= \begin{cases}1 & \text { if } P_{i}^{*}>0 \\ 0 & \text { otherwise }\end{cases}
$$

Because the error term in the estimated equation contains $u_{i}$, which is correlated with $B_{i}$, the estimated effect of benefits on the probability of participating in SSI will be biased. Ignoring the vector $\mathbf{X}_{\mathbf{i}}$ for the moment, the estimate of the effect of benefits from a simple probit analysis is downward biased and will converge to

$$
\frac{\delta \frac{\sigma_{B^{*}}^{2}}{\sigma_{B^{*}}^{2}+\sigma_{u}^{2}}}{\sqrt{\sigma_{e}^{2}+\delta^{2} \frac{\sigma_{B^{*}}^{2} \sigma_{u}^{2}}{\sigma_{B^{*}}^{2}+\sigma_{u}^{2}}}}
$$

(See Yatchew and Griliches 1985 for the derivation of this formula and a discussion of the bias introduced by various specification errors in a probit model.) This bias can be thought of as 
resulting from the impact of two effects which operate in the same direction. Measurement error directly biases the estimate by the familiar signal to noise ratio (numerator) and further reduces the estimate of $\delta$ by the increase in the variance of the error term (denominator).

In order to obtain a consistent estimate of the effect of the benefit, I use an instrumental variables procedure. I first predict the value of the expected benefit using an OLS regression. This predicted value then replaces the calculated amount in the probit equation. It is likely that some of the error in the calculated benefit comes from errors in reported income. I therefore use an average of reported monthly income, less reported SSI benefits, for the four month period covered by the previous wave as one of the instrumental variables for the amount of the SSI benefit. ${ }^{30}$ By using an average value rather than income for any particular month, I hope to minimize the influence of transitory shocks to income. The other variables in the first stage regression include marital status, whether the filing unit lives in their own household, and an indicator of the generosity of the SSI program in the state in which the unit lives. These variables are directly related to the official determination of the benefit level, yet they ought to be uncorrelated with current error, and so they are obvious choices for instrumental variables.

The model then becomes

$$
\begin{aligned}
B_{i}^{*} & =Z_{i} \gamma+v_{i}, v_{i} \sim N\left(0, \sigma_{v}^{2}\right) \\
B_{i} & =Z_{i} \gamma+v_{i}+u_{i} \\
B_{i} & =Z_{i} \hat{\gamma}+v_{i}+u_{i}+\left(Z_{i} \hat{\gamma}-Z_{i} \gamma\right)
\end{aligned}
$$

where $\hat{\gamma}$ is a consistent estimator of $\gamma$.

$$
\begin{aligned}
P_{i}^{*} & =\delta \hat{B}_{i}+\mathbf{X}_{\mathbf{i}} \alpha+\eta_{i} \\
\text { where } \eta_{i} & \stackrel{p}{\rightarrow} \delta v_{i}+e_{i}, \text { as }\left(Z_{i} \hat{\gamma}-Z_{i} \gamma\right) \stackrel{p}{\rightarrow} 0 \\
\text { and } \hat{B}_{i} & =Z_{i} \hat{\gamma} .
\end{aligned}
$$

Because I assume that $v$ and $e$ are normally distributed with zero mean, $\eta$ is also normally distributed and with a mean of zero. The model may be estimated by the usual maximum likelihood method. ${ }^{31}$ The estimates are presented in the columns of Table 2 labeled "Two Stage Probit."

\footnotetext{
${ }^{30}$ Including reported income for earlier waves did not change the results.

${ }^{31} \mathrm{As}$ in a simple probit, $\sigma_{e}^{2}$ is not identified; coefficent estimates are identified up to a scaling factor.
} 
This specification ignores the confounding effect of measurement error in the determination of eligibility, and therefore selection into the sample. As discussed in Sanders and Taylor (1994), this misclassification results in an estimate for the coefficient on the expected benefit which is biased.

The probability of participating in SSI, $P\left(\delta \hat{B}_{i}+\mathrm{X}_{\mathbf{i}} \alpha+\eta_{i}>0\right)$, can be written as

$$
\begin{gathered}
P\left(\delta \hat{B}_{i}+\mathbf{X}_{\mathbf{i}} \alpha+\eta_{i}>0 \mid \text { eligible }\right) * P(\text { eligible })+ \\
P\left(\delta \hat{B}_{i}+\mathbf{X}_{\mathbf{i}} \alpha+\eta_{i}>0 \mid \text { not eligible }\right) * P(\text { not eligible }) .
\end{gathered}
$$

I assume that the second term is 0 ; the probability of participation for those who are not eligible is zero. Thus far, I have also assumed that I have determined eligibility correctly: if $B_{i}>0$ the probability of being eligible is 1 . Similarly, if $B_{i} \leq 0$ the probability of being eligible is 0 . If this assumption is correct, I can simply estimate $P\left(\delta \hat{B}_{i}+\mathbf{X}_{\mathbf{i}} \alpha+\eta_{i}>0\right)$ over all those with $B_{i}>0$.

However, allowing for the possibility of measurement error in the calculated benefit, raises the possibility that the classification is also incorrect. Correct determination should be based on the actual benefit $B_{i}^{*}$ rather than on the calculated benefit, $B_{i}$, since $B_{i}=B_{i}^{*}+u_{i}$. However, $B^{*}$ is only observed for those in the sample who actually do participate in the program.

The probability of being truly eligible for benefits is $P\left(B_{i}^{*}>0\right)=P\left(B_{i}-u_{i}>0\right)$. Or, $\Phi\left(B_{i} / \sigma_{u}\right)$ if $u \sim N\left(0, \sigma_{u}^{2}\right)$. I assume that the reported value of the benefit $B_{i}^{*}$ is correct and estimate $\sigma_{u}$ from those in the sample for whom I observe both $B_{i}^{*}$ and my calculated value $B_{i}{ }^{32}$

$$
\hat{\sigma_{u}}=\sqrt{\frac{\sum_{i}\left(B_{i}^{*}-B_{i}\right)^{2}}{n}} \text {. }
$$

Using this value allows me to calculate a probability of being eligible for each individual in the sample as $\Phi\left(B_{i} / \hat{\sigma}_{u}\right)$. In this way the simple probit estimation can be corrected for the sample selection problem, as well as for the errors in variables problem described earlier. ${ }^{33}$

$$
P\left(\delta \hat{B}_{i}^{*}+\mathbf{X}_{\mathbf{i}} \alpha+\eta_{i}>0\right)=
$$

\footnotetext{
${ }^{32}$ This calculation differs somewhat from the difference between observed and calculated benefits discussed in section 4.2 in that the 23 SSI units whom I determine to be ineligible but who report a positive benefit are included here. The estimated value for $\sigma_{u}$ is 125 . The distribution of $\left(B_{i} / \sigma_{u}\right)$ broadly speaking follows the shape of a normal distribution and has a standard deviation of 2.3. However it is negatively skewed and the null hypothesis that it is normally distributed is rejected at a one percent level.

${ }^{33}$ This correction ignores measurement error in assets which may also affect the determination of eligibility. Because I do not have two observations of assets as I do for the SSI benefit (self-reported, and calculated from the state guidelines), I cannot obtain an estimates of the variance of the measurement error for assets by similar methods. However, given that assets operate as a 0/1 determinant of eligibility, and have no further impact on the magnitude of the expected benefit, I am far less concerned about possible biases in the estimated coefficients resulting from observation errors in assets, than I am for errors in the calculated benefit which directly enters the participation decision. However, to check the sensitivity of the results to the imposition of an asset test, I repeat this estimation procedure for a sample which include all individuals with assets within 150 percent of the SSI guidelines. The sample
} 


$$
\begin{gathered}
P\left(\delta \hat{B}_{i}^{*}+\mathbf{X}_{\mathbf{i}} \alpha+\eta_{i}>0 \mid \text { eligible }\right) * \Phi\left(B_{i} / \hat{\sigma_{u}}\right)+ \\
P\left(\delta \hat{B_{i}^{*}}+\mathbf{X}_{\mathbf{i}} \alpha+\eta_{i}>0 \mid \text { not eligible }\right) *\left[1-\Phi\left(B_{i} / \hat{\sigma_{u}}\right)\right]
\end{gathered}
$$

Again note that the second term in the above equation drops out because I assume that those who are not eligible do not participate. This specification in effect "weights" an individual's probability of participating in the SSI program by the probability that she is eligible for SSI. All those who have assets below the SSI limits contribute to the likelihood function. Units for whom I calculate a negative benefit (and who are therefore not included in either of the previous specifications) are "weighted" less heavily because they have a low probability of actually being eligible, while units with large calculated benefits are "weighted" more heavily.

Incorporating the earlier two stage procedure, the likelihood function is

$$
\Sigma_{i} P_{i} \ln \Phi\left(\frac{\delta \hat{B}_{i}^{*}+\mathbf{X}_{\mathbf{i}} \alpha}{\sqrt{\sigma_{e}^{2}+\delta^{2} \sigma_{\epsilon}^{2}+\delta^{2} \sigma_{u}}}\right) \Phi\left(\frac{B_{i}}{\sigma_{u}}\right)+\left(1-P_{i}\right) \ln \left(1-\Phi\left(\frac{\delta \hat{B}_{i}^{*}+\mathbf{X}_{\mathbf{i}} \alpha}{\sqrt{\sigma_{e}^{2}+\delta^{2} \sigma_{\epsilon}^{2}+\delta^{2} \sigma_{u}}}\right) \Phi\left(\frac{B_{i}}{\sigma_{u}}\right)\right)
$$

\section{Discussion of Results}

The estimates of the parameters and their standard errors are presented in Table $2 .{ }^{34}$ The results for the simple probit model (model 1), the instrumental variable procedure (model 2), and the "weighted" instrumental variable procedure (model 3), are shown. ${ }^{35}$ The broad conclusions are the same. When comparing the three sets of estimates, the change in the estimated coefficient for the expected benefit when moving from the first to either of the other two specifications is substantial. The derivative with respect to the benefit more than doubles increasing from 0.00097 to either 0.0023 to 0.0026 when the estimation procedures are changed. The importance of failing to control for measurement error will become more apparent when the impact of changes in the benefit levels is discussed in section 6.2. The similarity between the estimated effect of the expected benefit in model 2 and model 3, and the large difference between these two models and model 1, suggest that the effect of measurement error through errors in variables in the participation equation is greater that the effect of misclassification.

size increases from 1245 to 1384 units. Because the weight given these newly eligible units (their probability of being income-eligible for SSI) is small, the coefficient estimates are substantially unchanged. The coefficient on the expected benefit increases from 0.0068 to 0.0069 . Other changes are similarly small.

${ }^{34}$ The reported standard errors have not been corrected for the use of the predicted benefit. See Newey (1984) for a discussion of the correction for a general nonlinear case.

${ }^{35}$ Estimates from the first stage regression are reported in Appendix Table A1. 


\subsection{Implications for Theories of Nonparticipation}

The main conclusion to be drawn from these results is that the total value (in terms of the utility it provides rather than just the monetary amount) of the benefit is driving the participation decision. A higher expected monetary benefit significantly increases the probability of participation. The elasticity of the expected benefit, at approximately 0.5 in the two measurement error corrected models, is greater than that of any other variable. Furthermore, even after controlling for the size of the SSI payment, those with greater income to needs ratios are less likely to participate, as are those who own a home or other assets, or who have reported labor income at some time over the year. The effects of most of the variables which are assumed to influence the marginal value of the benefit, are significantly different from zero at the 10 percent level and operate in the expected direction.

A higher variance in monthly income decreases the likelihood of participation, though not significantly in all specifications. This result is consistent with the theory that temporary spells of eligibility induce a different response from apparently more permanent episodes. As discussed earlier, to the extent that marital status indicates the degree to which the present financial situation is likely to continue, the estimate of the coefficient for the marital status dummy is in agreement with this hypothesis. Couples are somewhat less likely to participate than singles, although the effect is insignificant.

The need for medical insurance is included in the determination of the value of the SSI program. Although the coefficient for the variable indicating poor health is significant and large, automatic eligibility for Medicaid and the interaction of this variable with poor health are not significantly different from zero. Furthermore, the interaction term is negative. Thus, it appears that the additional utility obtained from Medicaid is relatively unimportant in the participation decision. ${ }^{36}$

The alternative theories of participation which have been widely discussed do not appear to be supported by the model. Factors which are assumed to make getting to the Social Security office easier, such as owning a car, or living in an MSA, are negatively, rather than positively related to the probability of participation, although only MSA in the final specification is significantly different

\footnotetext{
${ }^{36}$ This result agrees with that obtain by Blank (1989). She finds that the existence of Medically Needy programs does not reduce participation in AFDC. Moffitt and Wolfe (1991) using what they believe is a more accurate estimate of the value of Medicaid find that the size of the expected benefit from Medicaid is significant, and positively related to the probability of participating in AFDC.
} 
from zero at a 5 percent level. Living with others is also hypothesized to increase access, yet it too operates in the opposite direction in two of the three models, and is never significantly different from zero. Poor health is expected to restrict mobility, yet it is positively related to participation.

It has also been proposed that the difficulty of filling out the required forms and dealing with the inherent bureaucracy deters participation. Again, the results of the estimation cast doubt on this hypothesis. Additional years of schooling decrease the likelihood of participation (perhaps because of different attitudes towards welfare). However, in support of this hypothesis, those who receive Social Security benefits ought to be somewhat more familiar with the application process do, in fact, do have a significantly greater probability of participating in two of the three specifications.

Speculation that lack of information deters eligible participants is also contradicted by these estimates: those with more schooling are less likely to participate as are those living in a metropoli$\tan$ area. Both of these variables are expected to be positively correlated with the availability of information. Here again, however, the receipt of Social Security (which may make an individual better aware of other available benefits) does have a significant influence on participation, though the dummy variable for age, which indicates whether the SSI program was in operation when the individual reached age 65 does not. Thus, there does not seem to be strong evidence that non-participants are, in general, uninformed about the program or removed from possible sources of information, though the importance of the receipt of Social Security income does suggest that information may play a small role.

The notion of a welfare stigma has received much attention, especially in the sociology literature. The evidence presented here confirms that there is some effect which deters participation if the utility gained from SSI is not greater than some fixed level. It is certainly plausible to attribute this fixed cost to a stigma effect. Typically, this stigma is thought to affect individuals of different demographic groups to varying extents. However, these factors do not appear to affect the participation decision to a significant extent. Age, race, gender, residence in a southern state, and residence in an MSA are all insignificant at a 5 percent level. However, except for living in an MSA, the signs are in the direction predicted by the stigma hypothesis. The coefficient on other welfare is significantly different from zero and supports a commonly held belief about stigma. Those receiving other welfare income are significantly more likely to participate in the SSI program.

Although the estimates do not rule out the existence of a stigma effect in determining partici- 
pation, the data suggest that a significant portion of the nonparticipation is not explained by this phenomenon. Approximately 16 percent of the eligible non-participants (based on the classification obtained from calculated benefits) are receiving benefits from other types of welfare; for 82 percent of these people, the other welfare is received from the Food Stamp Program. Individuals who are eligible for SSI are also eligible to receive food stamps in all but two states. ${ }^{37}$ Thus, almost all of those in the sample are eligible for food stamps as well as for SSI. Food stamp benefits are received in the form of coupons which are used instead of cash to pay for food. Because food stamps must be used in public, there ought to be more of a stigma associated with participation in this program than in SSI. For those who report receiving food stamps, but not SSI, it is likely that some factor other than a stigma effect prevents their participation.

The estimates presented here fail to support a number of explanations of nonparticipation which have been put forth in the literature. It appears that the decision to participate is based, for the most part, on the value which the eligible unit places on the receipt of the expected benefit, and is unaffected by the difficulty of applying or obtaining information on the program. ${ }^{38}$

\subsection{Comparison with Previous Work}

The SIPP data used in this study allow for an improvement over previous work with respect to determining eligibility. As discussed earlier, previous work was not able to determine accurately state supplements, or to apply the asset test. Studies also differ in which independent variables are included and none makes any attempt to control for measurement error. However, given that they are similar in several respects, it is useful to compare the results. I will draw a comparison between my work and the studies by Menefee et al. (1981), Warlick (1982), and Coe (1985).

The most interesting comparison is between the predicted effects of the magnitude of the benefit to which the individual is entitled. Unfortunately, even focusing on this easily interpretable variable comparison is difficult. Menefee et al. use only a dummy variable indicating that the benefit is less than $\$ 50$ a month so an exact comparison in this case is not possible. Warlick specifies a logistic

\footnotetext{
${ }^{37}$ California and Wisconsin "cash-out" food stamp payments meaning that SSI recipients in these states receive higher monthly benefits in lieu of the food stamp coupons.

${ }^{38}$ However, the results should be interpreted with caution. The estimated model is a reduced form version. The structural model cannot be estimated because many of the factors theorized to affect participation, such as stigma or lack of information are unobserved. It is likely that some variables affect participation through their influence on two or more factors. If a variable operates in opposite directions on different factors, its importance may be obscured (e.g. schooling may positively affect the probability of participation by making the application process less arduous, and negatively affect it by increasing the stigma the individual feels accepting welfare benefits).
} 
model, and Coe uses a linear probability model. This paper adopts a normal distribution. I use the constants suggested in Maddala $\left(1983\right.$, p.23) to scale the estimates. ${ }^{39}$ Converting estimates to their linear probability values so that differences are readily interpretable, I find similar effects between my models 2 and 3 , and the estimates from Coe, while the estimates from Warlick which are smaller by an order of magnitude. A $\$ 10$ increase in benefits, increases the probability of participating by approximately 2.5 percent here and in Coe's work, and by 0.4 percent in Warlick. Warlick's results likely differ because she does not include benefits from state supplemental programs. The other strong predictors in my study, schooling, welfare benefits, health status, and income, are not always controlled for and if they are, they are typically not significantly different from zero. Warlick finds, as I do, that those with more schooling are significantly less likely to participate while Coe finds insignificant effects. Menefee et al., find significant differences by health status, but Coe does not. Apparently the more complete set of covariates included here and the more accurate determination of benefits, helps to separate a number of confounding effects.

\subsection{Changes in Benefit Levels}

In this section I use the estimates in Table 2 to simulate the effects of various changes in benefits. Because models 2 and 3 imply similar effects and because model 3 is preferred to model 2, I report only the simulated changes in participation based on models 1 and 3 . I report both sets of predictions to emphasize the importance of controlling for measurement error.

The differences in the magnitude of the derivatives between the model 1 and either model 2 or model 3, suggest that simulated responses to changes in benefits will differ greatly depending on whether or not measurement error is controlled for. To compare the effect of changes in benefits, I evaluate the probability of participation for each model at the means of the right hand side variables. For the simple probit the probability of participating in SSI is calculated using the cumulative normal distribution, $\boldsymbol{\Phi}\left(\frac{\hat{\delta}}{\sigma_{e}} \bar{B}+\frac{\alpha}{\sigma_{e}} \overline{\bar{X}}\right)$. For the third model, the comparable value from the normal cumulative distribution function is scaled by the probability of being eligible, also evaluated at the mean, to construct the probability of participating in SSI conditional on being eligible. Simply increasing the mean benefit by 10 percent with no concurrent change in eligibility, increases the two participation rates by 1.4 percentage points, using the estimates of model 1 ,

\footnotetext{
${ }^{39}$ Probit coefficient estimates are divided by 2.5 and logit estimates divided by 4 to equate with the linear probability model.
} 
and by 2.4 percentage points with model 3 . The differences for larger increases are even more dramatic. A 25 percent increase in mean benefits increases the probability of participation by just 3.5 percentage points in the first case, compared with 6.1 in the second.

In $1984,1,397,319$ elderly singles, or married couples received benefits from the SSI program. At the participation rate of 0.534 predicted by model 3 , this figure corresponds to an estimated 2,616,702 eligible units. An increase in the participation rate to 0.595 (a 6.1 percentage point increase) implies an increase of 159,619 in the number of participants. Without the correction for measurement error, the predicted increase in the case load would be just 90,486 . These figures account only for changes in the decisions of those eligible under the present benefit scheduleclearly, additional units would become eligible if the guarantee were increased. The increased eligibility in the weighted two stage procedure would be seen through an across the board increase in the probability of being eligible. Below I simulate such a change.

In 1975 , the SSI study group suggested raising the federal SSI guarantee to the poverty line. ${ }^{40}$ Although this idea was not adopted, it has continued to be discussed (see Zedlewski and Meyer 1989). I therefore investigate how the participation rate would change were the benefit guarantees raised to this level. To examine the impact of increasing benefits to this extent, I increase the federal income guarantee accordingly, and assume that no state changes the value of its state supplement; the states with guarantees above the poverty line maintain these levels, and those with lower maximum benefits are freed of all payments. This assumption may not be realistic; many states may wish to continue to contribute some amount of assistance to their own elderly poor for example to account for state differences in the cost of living. However, it appears to be the most plausible assumption.

If the federal guarantees are raised to $\$ 415$ and $\$ 523$ for singles and couples, ${ }^{41}$ and the $1 / 3$ reduction for those living in the household of another retained, two changes take place. Those who are eligible at the original levels see their potential benefits increased, and they therefore become more likely to participate, and those who were initially ineligible may now be entitled to benefits. This latter group ought to have substantially lower expected benefits. The initial benefit calculated by weighting all 1245 observation by their probability of being eligible is $\$ 125$. The

\footnotetext{
${ }^{40}$ The poverty line for 1984 in monthly terms was approximately $\$ 415$ for a single individual and $\$ 523$ for a couple.

${ }^{41}$ This change results in an average increase in benefits of $\$ 81.39$ for singles and $\$ 52.99$ for couples.
} 
sum of the weights is 526 , indicating an eligible population of 526 units (compare with 554 eligible units obtained by ignoring measurement error in the determination of eligibility in models 1 and 2). When the federal guarantees are raised to the poverty level, the average benefit using the original probabilities of eligibility is $\$ 193$. This average simulates the value of the expected benefit for those who were eligible under the initial guarantees. This value implies an increase in the participation rate for this group of 16.5 percentage points, from a predicted participation rate of 0.534 to 0.699 .

Next, I assess the participation decision including the newly eligible. Using the average values of the explanatory variables for all units, weighted by the probability of being eligible at the new benefit levels, and the estimated coefficients of model 3, the predicted participation rate for the entire sample is just 0.605 percent, implying that the newly eligible participate at a much lower rate than those eligible at the original benefit levels. The sum of the eligibility weights indicates that the number of eligible units by has risen by 153 to 679 , and that only 28 percent of the newly eligible will participate. The average benefit for the entire sample using the new weights is $\$ 160$.

This change in the benefit guarantee increases the dollar value of total benefits received in my sample by 64 percent. Applying this figure to the total value of benefits paid to aged individuals in 1984 of $\$ 3$ billion, increases the total cost of benefits to the elderly to $\$ 4.9$ billion. Eighty-four percent of this increase in spending is due to the increase in the participation of those who were eligible at the original levels, the remainder is spent on the newly eligible.

\section{Conclusion}

The decision of so many elderly poor not to accept additional income is perplexing. By assuming that individuals who forego welfare income are behaving rationally, this paper has attempted to discover which of the costs associated with participation are most responsible for this behavior. It appears that enrollment in SSI is strongly related to need. There is also some weak evidence of a stigma effect, although its strength does not seem to be highly correlated with many observable characteristics. Neither of these factors offers much hope for the effective intervention of government policy. It is, however, comforting to note that there does not appear to be a large fraction of elderly poor who desire assistance and are unable to attain it because of transactions costs.

The data used in this study are from 1984-ten years after the program's inception. While a significant amount of time has past since these data were collected, it is doubtful that the conclusions 
of this paper would change were the model to be estimated with more recent data. The two most plausible explanations for changes since 1984 are that there exist information barriers which may decline over time as knowledge of the program spreads, or secondly, that changes in Medicaid regulations, which effectively separate participation in Medicaid from participation in other welfare programs, would reduce the number of individuals enrolling in the SSI program in order to receive the tied benefit of medicaid. I do not believe that either of these developments would significantly alter the results. First, it was speculated earlier in the paper that initial participation in 1974 may have been dampened due to information problems, yet I found no difference in overall participation rates between 1974 and 1984. Nor do the estimates of the models indicate that informational barriers are reducing participation. Thus, additional time ought not to affect participation through the spread of information. Furthermore, the availability of Medicaid through medically needy programs did not significantly affect participation, so one would not expect that the expansion of such programs over the years would have a strong impact.

This paper also provides evidence of the importance of controlling for observation error in this type of study. When measurement error is accounted for, the coefficient for the expected benefit changes significantly. The size of the change is dramatized by examining the change in the participation rate in response to a change in the average benefit. The effect of a 25 percent increase in the average SSI payment increases the probability of participating for those previously eligible by just 3.5 percentage points when measurement error is ignored, but by 6.1 percentage points in the instrumental variable procedures. Clearly future papers analyzing participation ought to pay careful attention to the role of measurement error. 


\section{Appendix}

To determine each unit's expected benefit from SSI, I first compare the value of assets to the limits imposed by the SSI program. If the unit passes the asset test, I calculate the value of the federal benefit to which the unit is entitled under federal regulations, taking into account all appropriate disregards. To calculate the state supplement, I again compare the unit's asset level to the maximum permitted by the laws of the specific state. For asset eligible units, I proceed to calculate countable income and the value of the expected state benefit, using state specific restrictions and guarantee levels. The unit will receive the larger of the two amounts, with the federal government first paying the amount to which the unit is entitled based on the federal legislation, and the state paying any supplementary monies. ${ }^{42}$

In deriving the expected benefit it is necessary to make some assumptions. The first relates to the asset test. The federal guidelines exclude the entire value of a car if it is needed for work or for medical treatments. If the car is not needed for either of these purposes, up to $\$ 4500$ of its value is still excluded. Since it is not possible from the available information to tell how the car is used, I exclude the total value of one car for each unit. If more than one car is owned, I exclude the value of the most expensive car. Only 15 of the 554 units which are eventually classified as eligible have a car worth more than $\$ 4500$, and only 11 eligible units have more than one car. Thus, this assumption is not expected to affect the results significantly. The limit on personal property and household furnishings is ignored. Other asset restrictions are handled straightforwardly as the necessary data are available.

With regard to the value of the benefit itself, several additional assumptions are required. While I aim to use state specific guarantees and restrictions for all observations, aggregation of observations for some states prohibits modeling their programs individually. Observations from Idaho, New Mexico, South Dakota, and Wyoming are combined as are observations from Mississippi and West Virginia. Benefits for the western group are calculated using the least generous program (New Mexico's). Since New Mexico does not have a supplemental program, I assume that no one in any of these states receives a state supplement. This assumption is unlikely to effect the results because even where supplements are offered they are small. The average supplement for all four of

\footnotetext{
${ }^{42}$ I ignore any mandatory state supplements. However, because so few individuals receive such benefits (see footnote 6 , this omission is unlikely to affect the results.
} 
these states is just $\$ 27$ over the federal level for singles, and $\$ 18$ for couples. The grouping of the two southern states does not pose any problem since neither Mississippi nor West Virginia supplement the federal benefit level. Consistently using the lowest guarantee levels implies that some eligible individuals will be incorrectly classified as ineligible. Using the largest guarantee implies the reverse. Thus, if the participation rate in this study is incorrect, it is somewhat overstated rather than understated.

Several other assumptions are required to deal with minor differences in state programs. In 1984 six states based the amount of their supplement on region of residence. To calculate the expected benefit in these cases I use the guarantee level reported in the U.S. Department of Health and Human Services (1984). If more than one value is reported, I select the lowest-a rule that is consistent with the practice adopted for the aggregated state categories. Ilinois awards supplemental benefits on a case by case basis. Since it is impossible to calculate an individual's benefit accurately in this state, I apply only the federal guarantee to determine eligibility. Finally, many states offer additional payments to those who need some sort of home care or medical attention. Where the data do not permit determination of the need for this type of assistance, I calculate only a federal payment. However, in some cases these special assistance levels can be used. Alabama, for instance, offers supplements to those living independently but requiring personal care. To indicate the need for personal care, I use the responses to questions in a section of wave 3 of SIPP which is devoted to health related issues. Individuals are assumed to require personal care if they answer that they need help with either, "looking after his/her personal needs," or "housework/meal preparation," and that they pay someone to provide this help.

A discussion of the accuracy of the calculated benefit is contained in section 4.2 of the text. 
Appendix Table A1

First Stage Regression Estimates for "Weighted" Probit

\begin{tabular}{lrr}
\hline \hline \multicolumn{1}{c}{ Variable } & Coeff & \multicolumn{1}{c}{ SE } \\
\hline & & \\
Average Income* & -0.3517 & 0.0148 \\
Not household head & -27.81 & 9.28 \\
Couple (1=married) & 131.27 & 10.09 \\
Generous State $(0 / 1)$ & 81.75 & 7.05 \\
\hline Number of observations & 1245 \\
$\mathrm{R}^{2}$ & 0.36 \\
\hline * Average monthly income in previous wave \\
\hline
\end{tabular}




\section{References}

[1] Baldus, David C. (1973): "Welfare as a Loan: An Empirical Study of the Recovery of Public Assistance Payments in the United States," Stanford Law Review, vol. 25, pp. 123-250.

[2] Blank, Rebecca (1989): "The Effect of Medicaid on AFDC Participation," Journal of Human Resources, vol. XXIV, no. 1, pp. 54-87.

[3] Coe, Richard (1985): "Nonparticipation in the SSI Program by the Eligible Elderly," Southern Economic Journal, vol. 51, no. 3, pp. 891-897.

[4] Fraker, Thomas and Robert Moffitt (1988): "The Effect of Food Stamps on Labor Supply: A Bivariate Selection Model," Journal of Public Economics, vol. 35, no. 2, pp. 25-56.

[5] Hurd, Michael D. and David A. Wise (1989) "The Wealth and Poverty of Widows: Assets Before and After the Husband's Death," The Economics of Aging ed. David A. Wise. Chicago: University of Chicago Press.

[6] Kalton, Graham, David B. McMillen, and Daniel Kasprzyk (1986): "Nonsampling Error Issues in the Survey of Income and Program Participation," SIPP Working Paper Series No. 8602. Washington D.C.: U.S. Bureau of the Census.

[7] Maddala, G.S. (1983): Limited Dependent and Qualitative Variables in Econometrics., New York : Cambridge University Press.

[8] Menefee, John, Bea Edwards, and Sylvester J. Schieber (1981): "Analysis of Nonparticipation in the SSI Program" Social Security Bulletin, vol. 44, no. 6, pp. 3-21.

[9] Moffitt, Robert (1983): "An Econometric Model of Welfare Stigma," The American Economic Review, vol. 73, no. 5, pp. 1023-1035.

[10] Moffitt, Robert and Barbara Wolfe (1991): "The Effect of the Medicaid Program on Welfare Participation and Labor Supply," unpublished paper.

[11] Myers, Robert J. (1985): Social Security. Homewood, Illinois : Richard D. Irwin Inc.

[12] Newey, Whitney K. (1984): "A Method of Moments Interpretation of Sequential Estimators," Economic Letters, vol. 14, pp. 201-206.

[13] Osgood, Mary H. (1977): "Rural and Urban Attitudes Toward Welfare," Social Work, vol. 22, pp. $41-47$.

[14] Sanders, Seth and Lowell Taylor (1994): "Race, Family Structure, and 'Social Stigma:' How Do They Affect Public Assistance Program Participation?" mimeo, Carnegie Mellon University.

[15] Sheilds, John F., Burt S. Barnow, Katherine A. Chaurette and Jill M. Constantine (1990): "Elderly Persons Eligible for and Participating in the Supplemental Security Income Program," Final Report prepared for the U.S. Department of Health and Human Services.

[16] Social Security Administration (1985): Social Security Bulletin Annual Statistical Supplement, 1984-1985, Social Security Administration.

[17] Social Security Administration (1984): The Supplemental Security Income Program for the Aged, Blind, and Disabled Selected Characteristics of State Supplementation Programs as of January 1984, Office of Supplemental Security Income, Social Security Administration.

[18] Social Security Administration (1984): The Supplemental Security Income Program for the Aged, Blind, and Disabled: Summary of State Payment Levels, State Supplementation and Medicaid Decisions. Office of Supplemental Security Income, Social Security Administration.

[19] Social Security Administration (1982): "Low Income Eligibility and Participation in SSI." Social Security Bulletin vol. 45 no. 5, pp. 28-35. 
[20] Strauss, Robert P. (1977): "Information and Participation in a Public Transfer Program," Journal of Public Economics, vol. 8, pp. 385-396.

[21] U.S. Bureau of the Census (1990): "Money Income and Poverty in the United States," Current Population Reports, Consumer Income, Series P-60, no. 168.

[22] Warlick, Jennifer L. (1982): "Participation of the Aged in SSI," Journal of Human Resources, vol. XVII no. 2, pp. 236-260.

[23] Warlick, Jennifer L. (1979): "An Empirical Analysis of Participation in the Supplemental Security Income Program Among Aged Eligible Persons," unpublished Ph.D dissertation, Department of Economics, University of Wisconsin.

[24] Yatchew, Adonis and Zvi Griliches (1985): "Specification Error in Probit Models," The Review of Economics and Statistics, vol. 67 no. 1 pp. 134-139.

[25] Zedlewski, Sheila R. and Jack A. Meyer (1989): Toward Ending Poverty Among the Elderly and Disabled Through SSI Reform, Washington D.C.: The Urban Institute Press. 
Table 1

Sample Means and Standard Deviations

\begin{tabular}{|c|c|c|c|c|c|c|}
\hline \multirow[b]{2}{*}{ Variable } & \multicolumn{2}{|c|}{ All } & \multicolumn{2}{|c|}{ Participants } & \multicolumn{2}{|c|}{ Nonparticipants } \\
\hline & Mean & Std. Dev. & Mean & Std. Dev. & Mean & Std. Dev. \\
\hline Calculated benefit* & 143.77 & $(125.29)$ & 176.89 & $(134.24)$ & 101.70 & $(98.14)$ \\
\hline Income less $\mathrm{SSI}^{*}$ & 258.23 & $(172.69)$ & 208.90 & $(148.79)$ & 320.89 & $(180.75)$ \\
\hline Variance in income over year $/ 10000^{*}$ & 2.79 & $(14.15)$ & 1.05 & $(5.16)$ & 5.01 & $(20.35)$ \\
\hline Age $(1$ if $<75)$ & 0.51 & $(0.50)$ & 0.51 & $(0.50)$ & 0.50 & $(0.50)$ \\
\hline Race (1 if non-white) ${ }^{*}$ & 0.31 & $(0.46)$ & 0.35 & $(0.48)$ & 0.26 & $(0.44)$ \\
\hline Gender (of eldest for couples, $1=$ female) ${ }^{*}$ & 0.76 & $(0.43)$ & 0.75 & $(0.44)$ & 0.79 & $(0.41)$ \\
\hline Highest grade attended (of eldest for couples) ${ }^{*}$ & 7.89 & $(5.08)$ & 6.90 & $(4.70)$ & 9.14 & $(5.28)$ \\
\hline Couple ( 1 if married) & 0.14 & $(0.35)$ & 0.14 & $(0.35)$ & 0.14 & $(0.35)$ \\
\hline Home ( 1 if own home) $)^{*}$ & 0.38 & $(0.48)$ & 0.31 & $(0.46)$ & 0.47 & $(0.50)$ \\
\hline SS (1 if receive Social Security) ${ }^{*}$ & 0.78 & $(0.41)$ & 0.70 & $(0.46)$ & 0.88 & $(0.32)$ \\
\hline Welfare ( 1 if receive other welfare) ${ }^{*}$ & 0.32 & $(0.47)$ & 0.45 & $(0.50)$ & 0.16 & $(0.36)$ \\
\hline South ( 1 if residence in South) ${ }^{*}$ & 0.47 & $(0.50)$ & 0.52 & $(0.50)$ & 0.40 & $(0.49)$ \\
\hline MSA ( 1 if residence in MSA)* & 0.47 & $(0.50)$ & 0.42 & $(0.49)$ & 0.52 & $(0.50)$ \\
\hline Car ( 1 if household owns a car $)^{*}$ & 0.21 & $(0.41)$ & 0.16 & $(0.37)$ & 0.27 & $(0.44)$ \\
\hline Others ( 1 if SSI unit lives with others) & 0.39 & $(0.49)$ & 0.39 & $(0.49)$ & 0.39 & $(0.49)$ \\
\hline Poor Health ( 1 if reports poor health $)^{*}$ & 0.40 & $(0.49)$ & 0.50 & $(0.50)$ & 0.27 & $(0.45)$ \\
\hline Eligible Medicaid ( 1 if SSI guarantees Medicaid) & 0.77 & $(0.42)$ & 0.77 & $(0.42)$ & 0.76 & $(0.43)$ \\
\hline Poor Health $\mathrm{x}$ Eligible Medicaid* & 0.29 & $(0.45)$ & 0.36 & $(0.48)$ & 0.20 & $(0.40)$ \\
\hline Earnings ( 1 if had labor earnings this year) ${ }^{*}$ & 0.05 & $(0.22)$ & 0.01 & $(0.11)$ & 0.09 & $(0.29)$ \\
\hline Assets ( 1 if had non-zero countable assets $\left.{ }^{\dagger}\right)^{*}$ & 0.31 & $(0.46)$ & 0.25 & $(0.43)$ & 0.40 & $(0.49)$ \\
\hline Income / poverty line* & 0.59 & $(0.37)$ & 0.48 & $(0.33)$ & 0.74 & $(0.38)$ \\
\hline Number of observations & 554 & & 310 & & 244 & \\
\hline
\end{tabular}

* Means are significantly different at the 1 percent level

$\dagger$ Countable assets equal total assets less disregards (see text). 
Table 2

Estimated Coefficients

(standard errors in parentheses)

\begin{tabular}{|c|c|c|c|c|c|c|}
\hline \multirow[t]{2}{*}{ Parameter } & \multicolumn{2}{|c|}{ Simple Probit } & \multicolumn{2}{|c|}{ Two Stage Probit } & \multicolumn{2}{|c|}{ Weighted } \\
\hline & Coeff & SE & Coeff & $\mathrm{SE}^{\dagger}$ & Coeff & $\mathrm{SE}^{\dagger}$ \\
\hline Intercept & 0.1907 & 0.4202 & -0.3785 & 0.4950 & -0.7436 & 0.5465 \\
\hline Calculated benefit & 0.0025 & 0.0008 & 0.0063 & 0.0018 & 0.0068 & 0.0017 \\
\hline Age $(1$ if $<75)$ & 0.0748 & 0.1249 & 0.0540 & 0.1257 & 0.1209 & 0.1635 \\
\hline Race ( 1 if non-white) & 0.1185 & 0.1422 & 0.1713 & 0.1428 & 0.3112 & 0.1963 \\
\hline Gender (of eldest for couples, $1=$ female) & -0.1108 & 0.1781 & -0.0687 & 0.1792 & -0.0944 & 0.2261 \\
\hline Highest grade attended (of eldest for couples) & -0.0279 & 0.0128 & -0.0251 & 0.0128 & -0.0307 & 0.0153 \\
\hline Couple ( 1 if married) & -0.0058 & 0.2394 & -0.3195 & 0.2724 & -0.4074 & 0.2970 \\
\hline Home ( 1 is own home) & -0.4326 & 0.1453 & -0.3979 & 0.1448 & -0.6451 & 0.1960 \\
\hline SS ( 1 if receive Social Se & 0.4426 & 0.2259 & 0.2745 & 0.2114 & 0.3521 & 0.2448 \\
\hline Welfare ( 1 if receive other & 0.7939 & 0.1478 & 0.7928 & 0.1474 & 1.0363 & 0.2164 \\
\hline South (1 if residence $i$ & 0.0947 & 0.1586 & 0.2263 & 0.1691 & 0.3784 & 0.2122 \\
\hline MSA ( 1 if residence in MSA) & -0.2391 & 0.1527 & -0.1901 & 0.1512 & -0.3848 & 0.1925 \\
\hline Car ( 1 if household owns a car & -0.2004 & 0.1721 & -0.1730 & 0.1756 & -0.1655 & 0.2163 \\
\hline Others ( 1 if SSI unit lives with others) & -0.1113 & 0.1366 & -0.1280 & 0.1354 & 0.1641 & 0.1737 \\
\hline Poor Health ( 1 if reports poor health) & 0.5740 & 0.2642 & 0.5863 & 0.2660 & 0.9086 & 0.3923 \\
\hline Eligible Medicaid (1 if SSI guarantees Medicaid) & 0.1538 & 0.2005 & 0.0527 & 0.2045 & 0.1559 & 0.2397 \\
\hline Poor Health x Medicaid & -0.0092 & 0.3048 & -0.0169 & 0.3069 & -0.2592 & 0.4404 \\
\hline Earnings ( 1 if had labor earnings this year) & -0.7484 & 0.3430 & -0.7145 & 0.3509 & -1.1369 & 0.3842 \\
\hline Assets ( 1 if had non-zero countable assets ${ }^{\ddagger}$ ) & -0.2082 & 0.1371 & -0.1912 & 0.1379 & -0.2665 & 0.1719 \\
\hline Variance of income over year & -0.0194 & 0.0096 & -0.0150 & 0.0096 & -0.0054 & 0.0111 \\
\hline Income / poverty line & -0.9646 & 0.2747 & -0.9007 & 0.2744 & -0.0567 & 0.2568 \\
\hline Number of Observations & 554 & & 554 & & 1245 & \\
\hline
\end{tabular}

$\dagger$ These are the uncorrected standard errors. See Newey (1984) for the appropriate correction in the general case.

$\ddagger$ Countable assets equal total assets less disregards (see text). 